\title{
Massively bleeding Dieulafoy lesion and unique rescue: a video based case report from National Liver Institute, Menoufia University
}

\author{
Omkolsoum Alhaddad, Maha Elsabaawy ${ }^{*}$ (D) Ahmed Elfaioumy and Ashraf Eljaky
}

\begin{abstract}
Background: Dieulafoy arteriole is a lamina propria vessel that unlike the other arterioles is getting bigger and bending into the mucosa of the gastrointestinal tract. Such anatomic aberration is unusual cause for life threatening gastrointestinal bleeds.

Case presentation: Herein, we report a case of an elderly gentleman, who had massively bleeding Dieulafoy lesion and endoscopic hemostasis of the spurting Dieulafoy by the use of the over-the-scope clip (OVESCO, Tübingen, Germany) has been successfully undertaken.

Conclusion: The endoscopic management of Dieulafoy related bleeds can be enriched by the use of over-thescope clip, OVESCO, technique.
\end{abstract}

Keywords: Dieulafoy lesion, OVESCO clip, bleeding, management

\section{Background}

A Dieulafoy lesion is a dilated tortuous arteriole abnormally protruding into the mucosa of the gastrointestinal tract [1]. Dieulafoy arteriole is a very infrequent lesion mostly appearing in the lesser curvature of the stomach [1]. Many reports described Dieulafoy lesions in other parts of the gastrointestinal tract [2-7].

Professor Georges Dieulafoy had described the lesion in a small series in 1894 \& believed it is a precursor of an ulcer [8]. Before Dieulafoy, in 1849, Dr. Gallard published three cases of Dieulafoy associated gastric ulcerations \& fatal massive bleeding [9]. However, Dieulafoy had more comprehensive narrative of the condition.

Dieulafoy arteriole can either rupture or erode into the mucosa portraying up to $5 \%$ of acute upper gastro- intestinal bleeds [10]. Bleeding from Dieulafoy is typically massive, and along endoscopic recognition of the oozing

\footnotetext{
* Correspondence: maha.ahmed@liver.menofia.edu.eg

Department Of Hepatology and Gastroenterology, National Liver Institute, Menoufia University, Shebeen El-Koom 32511, Egypt
}

erosion can be quite difficult [1]. Water-jet irrigation technique particularly along the lesser curvature has been described to permit recognition of the spurting arteriole or to remove the tiny fibrin clot over the Dieulafoy lesion, hence, provoking bleeding and visualization of the lesion [11].

Most recently, the large subsurface Dieulafoy arteriole can by promptly identified by using the doppler quality of endoscopic ultrasound (EUS) [12]. However, Dieulafoy lesion should be implied in every case of obscure gastrointestinal hemorrhage [1].

\section{Case presentation}

Here, we are reporting a case of 70-year-old gentleman, who presented feebly to the emergency unit of the $\mathrm{Na}$ tional Liver Institute, Menoufia University, complaining of successive vomiting of huge amounts of fresh blood. His relatives negated any previous similar condition. They reported poor control of his insulin dependent diabetes mellitus, which was diagnosed 10 years earlier. 
They gave history of myocardial infarction on mid-2014, with coronary care admission and placement of three coronary stents. Since that time, the patient is regularly on small dose salicylates and clopidogrel.

Imperative physical and hemodynamic assessment revealed a pale drowsy old man with a full-blown picture of shock: his blood pressure was $80 / 50 \mathrm{mmHg}$, pulse was 120 beat $/ \mathrm{min}$, and a respiratory rate of 24 breath/ min. Anti-shock measures were promptly administered with blood grouping for preparing red blood cell packs.

Laboratory research revealed severe anemia, and leukocytosis. The critically deficient hemoglobin concentration $(4 \mathrm{mg} / \mathrm{dl})$ had mandated urgent blood transfusion of five units of packed red blood cells. After six hours of unremitting resuscitation, and once being stabilized, the patient was referred to the endoscopy unit where an ulcer with visible vessels (Forrest 1B) $5 \mathrm{~cm}$ below the cardia on the greater curvature was well-defined, accordingly, an argon plasma electro-cautery and hemo-clips were applied for proper hemostasis. Securely, the patient was referred to the ward with dedicated follow-up. Unluckily, two days later, he suffered a second profound attack of hematemesis and along with intravenous fluids, he was immediately transferred to the endoscopy unit. The endoscopist witnessed a healed status for the previously treated ulcer and surprisingly, a fundal Dieulafoy spurting lesion was evident. The spurter was injected by 5 ampoules cyanoacrylate and bleeding was efficiently stopped.

Again, two days later, the patient had his third attack of massive hematemesis. A third upper endoscopy revealed recurred bleeding from the previously injected Dieulafoy spurter. The decision was determined to use the Ovesco clipping technique as a last weapon for combatting the relapsed Dieulafoy bleeding. An experienced endoscopist successfully deployed the clip and bleeding was instantly stopped (video 1 and 2).

The patient remained stabilized, and a second look -endoscopic examination- has revealed proper healing (video 3).

\section{Discussion}

Professor Georges Dieulafoy had described Dieulafoy arteriole a century and half ago, yet, the pathogenesis and the mechanism of bleeding from this vascular anomaly had not been precisely appreciated [7]. Minor trauma to a point in the mucosa which is pressurized by the enlarged dilated arteriole has been postulated as the likely mechanism for a bleeding Dieulafoy arteriole [13].

Implication of endoscopy in the diagnosis and management of the bleeding Dieulafoy has reduced the need for surgical intervention, also, reduced high mortality perpetually ascribed for this condition [14].
The reported endoscopic definitions of Dieulafoy lesions are ranging from an arterial spurting, small pulsatile streaming from a minute $(<3 \mathrm{~mm})$ mucosal defects, a protruding vessel with or without active bleeding within a minute mucosal defect with normal surrounding mucosa to an adherent clot attached to a minute mucosal defect or a normally appearing mucosa [15].

Endoscopic techniques to obtain hemostasis in Dieulafoy bleeds have been progressing over time. From old to recent, pure injection therapy of adrenaline $(1: 10,000)$ or cyanoacrylate glue to combined injection therapy and either hemoclips, argon plasma electro-cautery or band ligation are all used as alternative endoscopic procedures in management of Dieulafoy bleeds [16, 17]. The reported success rate of these different endoscopic techniques is varying between 75 to $98 \%$ [1].

Pure injection endoscopic management, leukocytosis, reduced prothrombin concentration and the use of antiplatelet drugs have been mentioned in many studies as predictors for rebleeding of Dieulafoy lesion after first endoscopic hemostasis $[18,19]$.

The case in this report has received only cyanoacrylate injection as the primary endoscopic management, additionally he was under aspirin treatment for his cardiac insufficiency. Hence, he was prone for rebleeding after apparently primary endoscopic hemostasis.

Up till now, a consensus treatment for Dieulafoy bleeding is not available and different modalities are used depending on the patient's presentation and the endoscopic experience of the endoscopy personnel [20].

Ovesco clip (Tübingen, Germany), an over-the-scope clip is nitinol, biocompatible and mounted on an applicator cap. The Ovesco clip is endoscopically deployed into the bleeding Dieulafoy in a resembling manner to variceal band ligation [21]. The key to successful deployment is staying calm, lining up the lesion, suction and then deployment.

The few publications concerning the use of the over scope clipping technique in management of Dieulafoy bleeds have shown remarkable hemostatic achievements [21-23]. Hence, Ovesco clipping was chosen in purpose to obtain adequate hemostasis in this case after failure of the first cyanoacrylate and re-bleeding. Proper healing of the Dieulafoy lesion which was documented in the follow-up endoscopic examination has confirmed the effectiveness, of the Ovesco clipping technique in the management of such a critical case.

\section{Conclusion}

This is the first report from the National Liver Institute, Menoufia University, describing successful use of the Ovesco clip in obtaining hemostasis of a massively spurting Dieulafoy lesion. Ovesco clipping can be proposed as the first line treatment for Dieulafoy bleeds. 


\section{Abbreviations}

OVESCO: Over the scope; EUS: Endoscopic ultrasound

\section{Supplementary Information}

The online version contains supplementary material available at https://doi. org/10.1186/s43066-021-00137-0.

Additional file 1: Video 1. The Dieulafoy spurter.

Additional file 2: Video 2 . The deployment of OVESCO clip.

Additional file 3: Video 3. The properly healed Dieulafoy leision.

\section{Acknowledgements}

All authors are indebted to Professor/ Omkolsoum Alhaddad for her great efforts in fulfilling this work

\section{Authors' contributions}

EO analyzed and interpreted the patient data and was a major contributor in writing the manuscript. EM helped in writing and revising the manuscript. EA was responsible on the clinical follow -up of the case. EA performed the endoscopic interventions. All authors read and approved the final manuscript.

\section{Funding}

No funding resources.

\section{Availability of data and materials}

All the data is available in the manuscript

\section{Declarations}

Ethics approval and consent to participate

The case was written after the consent of the ethical committee of National Liver Institute Menoufia University

\section{Consent for publication}

Written informed consent was obtained from the patient for publication of this case report and accompanying images".

\section{Competing interests}

All authors declare that they had no conflict of interest.

Received: 17 February 2021 Accepted: 27 July 2021

Published online: 12 September 2021

\section{References}

1. Nojkov B, Cappell MS (2015) Gastrointestinal bleeding from Dieulafoy lesion: Clinical presentation, endoscopic findings, and endoscopic therapy. World J Gastrointest Endosc 7(4):295-307. https://doi.org/10.4253/wjge.v7.i4.295

2. López-Arce G, Zepeda-Gómez S, Chávez-Tapia NC, García-Osogobio S, Franco-Guzmán AM, Ramírez-Luna MA, Téllez-Ávila FI (2008) Upper gastrointestinal Dieulafoy lesions and endoscopie treatment: first report from a Mexican Centre. Ther Adv Gastroenterol 1(2):97-101. https://doi. org/10.1177/1756283X08096285

3. Jaspersen D, Körner T, Schorr W, Brennenstuhl M, Hammar CH (1994) Extragastric Dieulafoy disease as unusual source of intestinal bleeding. Esophageal visible vessel. Dig Dis Sci 39(12):2558-2560. https://doi.org/10.1 007/BF02087690

4. Yılmaz TU, Kozan R (2017) Duodenal and jejunal Dieulafoy lesions: optimal management. Clin Exp Gastroenterol 10:275-283. https://doi.org/10.2147/ CEG.S122784

5. Sathyamurthy A, Winn JN, Ibdah JA, Tahan V (2016) Culprit for recurrent acute gastrointestinal massive bleeding: "Small bowel Dieulafoy lesions" - a case report and literature review. World J Gastrointestinal Pathophysiol 7(3): 296-299. https://doi.org/10.4291/wjgp.v7.i3.296

6. Jain A, Karegar M, Joshi A, Rojekar E (2018) Ileal Dieulafoy Lesion: a rare case report. Surg Exp Pathol 1:6

7. Inayat F, Hussain A, Yahya S, Weissman S, Sarfraz N, Faisal M, Riaz I, Saleem S, Saif M (2020) Rectal Dieulafoy's lesion: a comprehensive review of patient characteristics, presentation patterns, diagnosis, management, and clinical outcomes. Transl Gastroenterol Hepatol. https://doi.org/10.21037/tgh.2020. 02.17

8. Senger $J$, Rani Kanthan R (2012) The Evolution of Dieulafoy Lesion Since 1897: Then and Now-A Journey through the Lens of a Pediatric Lesion with Literature Review. Gastroenterol Res Pract 432517:8

9. Karamanou M, Fiska A, Demetriou T, Androutsos G (2011) Georges-Paul Dieulafoy (1839-1911) and the first description of "exulceratio simplex". Ann Gastroenterol 24(3):188-191

10. Gurzu S, Copotoiu C, Molnar C, Azamfirei L, Jung I (2014) Lethal gastric hemorrhage from a caliber-persistent artery of the antrum - a branch of the right gastric artery. Hippokratia. 18(2):172-176

11. Baxter M, Aly EH (2010) Dieulafoy's lesion: current trends in diagnosis and management. Ann R Coll Surg Engl 92(7):548-554. https://doi.org/10.1308/ $003588410 \times 12699663905311$

12. Enomoto S, Yahagi N, Fujishiro M, Oka M, Kakushima N, Iguchi M, Yanaoka K, Arii K, Tamai H, Shimizu Y, Omata M, Ichinose M (2007) Novel endoscopic hemostasis technique for use during endoscopic submucosal dissection. Endoscopy. 39(1):E156. https://doi.org/10.1055/s-2006-925254

13. Jensen D, Kovacs T, Ohning G, Ghassemi K, Machicado G, Gareth S, Dulai G, Sedarat A, Gornbein J (2017) Doppler Endoscopic Probe Monitoring of Blood Flow Improves Risk Stratification and Outcomes of Patients with Severe Nonvariceal Upper Gastrointestinal Hemorrhage. Original research full report: clinical-alimentary tract 152(6):1310-1318.e1

14. Juler GL, Labitzke HG, Lamb R, Allen R (1984) The pathogenesis of Dieulafoy gastric erosion. Am J Gastroenterol 79(3):195-200

15. Joarder Al, Faruque MS, Nur-E-Elahi M, Jahan I, Siddiqui O, Imdad S, Islam MS, Ahmed HS, Haque MA (2014) Dieulafoy's lesion: an overview. Mymensingh Med J 23(1):186-194

16. Jeon HK, Kim GH (2015) Endoscopic Management of Dieulafoy's Lesion. Clin Endosc 48(2):112-120. https://doi.org/10.5946/ce.2015.48.2.112

17. Jiang Y, Hu J, Li P, Jiang W, Liang W, Wei H (2018) A Retrospective Analysis of Cyanoacrylate Injection versus Hemo-clip Placement for Bleeding Dieulafoy's Lesion in Duodenum. Gastroenterol Res Pract 26:3208690

18. Massinha P, Cunha I, Tomé L (2020) Dieulafoy Lesion: Predictive Factors of Early Relapse and Long-Term Follow-Up. GE Port J Gastroenterol 27(4):237243. https://doi.org/10.1159/000504720

19. Shin HJ, Ju J, Jensen DM, Kovacs TOG, Ohning GV, Ghassemi K, Machicado GA, Dulai GS, Sedarat A, Jutabha R, Gornbein J (2017) Doppler Endoscopic Probe Monitoring of Blood Flow Improves Risk Stratification and Outcomes of Patients with Severe Nonvariceal Upper Gastrointestinal Hemorrhage. Gastroenterology 152(6):1310-1318.e1

20. Amarnath S, Ghimire S, Khan HM (2020) A Tale of Three Dieulafoy Lesions: A Case Report and Review of the Literature. Cureus 12(5):e8365. https://doi. org/10.7759/cureus.8365

21. Alcívar M, Ruiz M, Oleas R, Baquerizo-Burgos J, Robles-Medranda C (2018) Clip Ovesco ${ }^{\circledast}$ como tratamiento de rescate en lesión de Dieulafoy duodenal con sangrado activo [Ovesco clip as a rescue treatment of duodenal Dieulafoy lesion with active bleeding]. Rev Gastroenterol Peru 38(4):374-376

22. Gómez V, Baig K, Lukens T (2013) Woodward Novel treatment of a gastric Dieulafoy lesion with an over-the-scope clip. Endoscopy 45(S 02):E71

23. Skinner M, Gutierrez JP, Neumann H, Wilcox CM, Burski C, Mönkemüller K (2014) Over-the-scope clip placement is effective rescue therapy for severe acute upper gastrointestinal bleeding. Endosc Int Open 2(1):E37-E40. https://doi.org/10.1055/s-0034-1365282

\section{Publisher's Note}

Springer Nature remains neutral with regard to jurisdictional claims in published maps and institutional affiliations. 